\title{
Dairy farmers' expectations and receptivity regarding animal welfare advice: A focus group study
}

\author{
S. L. Croyle, ${ }^{*}$ E. Belage, D. K. Khosa, S. J. LeBlanc, D. B. Haley, and D. F. Kelton \\ Department of Population Medicine, University of Guelph, ON N1G 2W1, Canada
}

\section{ABSTRACT}

Discussion and incorporation of best practices for animal welfare have been increasing in research, and in commercial operations, including through welfare assessment initiatives. The aim of this study was to explore dairy farmers' perceptions about being approached and receiving advice about animal welfare (i.e., lameness, hock injuries, and disbudding practices). It is useful for dairy consultants, researchers, or animal welfare assessment programs to gain an in-depth understanding of farmers' expectations when broaching the subject of animal welfare issues to facilitate communication about what can be perceived as a sensitive topic. We collected qualitative data using a focus group methodology. Five focus groups of farmers $(\mathrm{n}=36$ in total), took place in Ontario, Canada. Discussions were audio-recorded and transcribed verbatim. Participant age ranged from 21 to $80 \mathrm{yr}$ (median $=47)$. Represented herd size ranged from 25 to 550 milking cows $($ median $=75)$. Farm type included free stall $(\mathrm{n}=14)$ and tie stall $(\mathrm{n}=22)$. Rigor was incorporated by using systematic thematic analysis: transcripts were coded line by line, and codes were categorized and then expanded and collapsed into themes, which were further refined to reflect farmer perceptions in a thematic map. Thematic analysis of the focus group discussions suggested 6 major themes related to farmers' receptivity to and expectations of animal welfare advice. Themes 1 to 4 provided insights into what farmers expected from those who were broaching topics: (1) an established relationship with the farmer; (2) expertise in dairy care/welfare; (3) prevention of "barn blindness"; and (4) provision of animal care services before and after welfare issues are broached. Theme 5 helped determine how welfare topics should be broached: the communication approach. Theme 6

Received October 9, 2018

Accepted April 22, 2019.

*Corresponding author: scroyle@uoguelph.ca identified who farmers feel should broach animal welfare topics on farm. Focus group discussions also provided insights into potential disconnects between farmer and veterinary expectations about animal welfare issues during herd health visits. Those who have established relationships with farmers are better received and are expected to broach welfare issues, especially if they are perceived to be an expert in animal care and welfare, and if they communicate the issue tactfully and work with the farmer to establish a plan of action.

Key words: communication, herd health, vet-client relationship, barn blindness

\section{INTRODUCTION}

Welfare issues such as lameness and hock injuries affect one-quarter to one-half of cows on dairy farms, on average (von Keyserlingk et al., 2012; Croyle et al., 2018). Although these welfare issues are prevalent, dairy industry stakeholders, including farmers, have ranked welfare as a top management issue on dairy farms, expressing a need to make it a priority for research (Bauman et al., 2016). Although welfare is an issue, we believe that farmers care about welfare, and that investigating farmer perceptions and exploring potential communication barriers can help to improve welfare issues on farm. Internationally, animal care assessments for dairy cows are used increasingly (Mench, 2003) through initiatives such as Farmers Assuring Responsible Management (http://www.nationaldairyfarm .com) in the United States, Red Tractor Assurance (https://assurance.redtractor.org.uk/) in the United Kingdom, and proAction Animal Care Assessment (https://www.dairyfarmers.ca/proaction) in Canada. These programs aim to measure and monitor the prevalence of animal care issues (e.g., lameness and hock injuries) at a program-dependent frequency (e.g., once per year), and they bring increased general awareness of welfare topics assessed, more conversation around welfare, and ideally, improved welfare over time. Although such programs can enlighten farmers by pointing out a welfare issue, they provide information as part of an 
assessment rather than a consultation, and assessments are often separated by long intervals. As a result, there can be a lack of conversation, potentially leading to a lack of understanding and trust on the part of the farmer. Although farmers are starting to receive assessment guidelines and feedback from assessments, little is known about farmers' general perspectives on being approached about animal welfare issues and working to resolve them on their farms. Rigorous research methods have not been applied to explore when, if, how, or by whom farmers want welfare issues to be broached and addressed on farm.

The role of the veterinarian has been shifting, from providing individual animal care to providing advice and consultation (LeBlanc et al., 2006). Other service providers, advisors, and mandated assessors are becoming increasingly involved in bringing welfarerelated information to farmers' attention. Therefore, it is important that veterinarians and other consultants understand their clients' expectations about animal welfare advice and associated communication on this topic. Some limited evidence through observation and discussion with veterinarians shows that responsibilities to both clients and animals can make discussions about animal welfare challenging (Morgan, 2009; Meijboom, 2018); a knowledge gap exists about farmers' perspectives.

The mandatory proAction assessment program in Canada was being implemented during the time of this study, so we expected that Canadian dairy farmers might be engaging in discussions about animal care with stakeholders in the industry (i.e., other farmers, veterinarians), creating a contextually unique opportunity to ask farmers about their experiences, expectations, and perspectives with respect to assessing and discussing welfare issues on their farms. To investigate farmers' perspectives (i.e., expectations around welfare assessment and communication), qualitative methods are often used. Focus groups are used in qualitative research to enhance conversation among peers, gather multiple points of view, and maximize the richness of the data collected (Creswell, 2007). Recently, qualitative methods using focus groups and interviews have been applied to understanding livestock farmers' beliefs about herd health issues, such as calf health (Sumner et al., 2018), veterinary roles for herd health in sheep (Kaler and Green, 2013), and motivation for hoof health changes (Bruijnis et al., 2013).

Our aim was to apply a rigorous qualitative methodology, exploring dairy farmers' perceptions of receiving advice on animal welfare issues on their farms. Specifically, we wanted to identify farmers' expectations about veterinarians broaching welfare issues and their receptivity to discussions about welfare topics.

\section{MATERIALS AND METHODS}

The study protocol was reviewed and approved by the University of Guelph Ethics Board (REB\#16NV021).

\section{Positionality Statement}

Positionality refers to the stance or viewing lens of the researcher in relation to the social context of the study. The researcher's positionality can affect what they choose to investigate and the angle of investigation, and it can also influence interpretation (Malterud, 2001; Cohen and Crabtree, 2008). As a veterinarian and researcher in the area of dairy cattle welfare, the primary author of this paper, S. L. Croyle, was aware of general veterinary responsibilities and was familiar with current welfare issues on dairy farms (e.g., hock injuries). However, the author lacked an understating of what it is like to be a farmer who is being evaluated on the welfare of their herds, and wanted to know more to provide insight to other consultants and researchers who may identify welfare issues on farm. This qualitative study involved focus groups designed from a critical realist perspective, which recognizes that in context, people attach meaning to experiences. Farmers in this study had lived experiences (e.g., relationships with advisors on welfare topics or relationships with assessment program personnel) and had developed expectations for discussions about welfare, which is in line with the critical realist's approach. Through such experiences, opinions, and attitudes, farmers can formulate viewpoints about how and from whom they want to receive animal welfare advice. This aspect of social science is important for understanding why farmers may be receptive to advice on welfare, and why they may implement it. Relationships (such as those with advisors) can have causal effects that can both enable and constrain what individuals can accomplish (e.g., improving a welfare issue on farm) when managing a business (i.e., a dairy farm; Easton, 2002; Storbacka and Nenonen, 2009). Studying farmers' perspectives on their relationship with those giving welfare advice is important, and is why the focus of this study was on how farmers perceived advice-giving, and how this related to their social processes.

\section{Study Design}

Focus groups were chosen as a means of collecting detailed information about both personal and group sentiments (Krueger and Casey, 2015) related to farmers' receptivity and communication with those seeking to broach and discuss animal care issues. Farmers were recruited through advertisements distributed at local 
farmer meetings and distributed by key informants, including veterinarians and nutritionists. Farmers were also enrolled using snowball sampling recruitment, through which some farmers invited others to join. Participants could call or e-mail to express interest, and they were then asked to invite other local dairy farmers. We recruited 7 to 10 participants for each focus group, an effective group size to encourage open discussion (Krueger and Casey, 2015). Participants were given an honorarium of $\mathrm{CA} \$ 100$ (1 CA $\$=\mathrm{US} \$ 0.74$ ) for their travel efforts, time, and participation. To be eligible for the study, participants had to be at least 18 years old, and a dairy farmer owning or leasing milk quota in Ontario. This manuscript was prepared and criteria were checked using the Consolidated Criteria for Reporting Qualitative Research (Tong et al., 2007).

\section{Interview Guide, Data Collection, Analysis}

A trained and experienced facilitator (SLC) moderated the focus group discussions, which were audio-recorded and professionally transcribed to produce a verbatim account of all discussions. The focus groups took place at community centers (e.g., libraries) convenient to participants' farms. Participants had no previous relationship with the facilitator. The facilitator discussed study objectives with the participants and informed them that the facilitator was a $\mathrm{PhD}$ candidate looking to gain insight into their perspectives related to welfare communication. Participants were not informed that the facilitator was a veterinarian, because we did not want to bias discussions about veterinarians. A semistructured interview guide with preplanned prompts was used to ensure that the same core questions were asked for all groups. Before the focus groups, the interview guide was tested by 3 dairy farmers to ensure clarity and understanding of questions. We used a range of strategies - such as "playing devil's advocate" or asking farmers for "worst-case scenarios" - to minimize the risks of "groupthink," in which participants might censor and shape their answers to fit with those of dominant group members (MacDougall and Baum, 1997; Krueger and Casey, 2015). We asked questions pertaining to communication about animal care and broaching animal care topics. All questions were open-ended and were followed up by prompts (e.g., What made you come to that conclusion?) to gain insight into farmers' perspectives. During the focus groups, we asked farmers general questions about animal care issues (e.g., What do you feel are the main animal welfare issues within dairy farms today? and Who do you feel is responsible for overseeing animal welfare on your farms?). We also asked about resources for animal care issues (e.g., Where would you seek information before or after an animal care assessment?). We asked farmers to discuss experiences in which someone brought an animal care issue to their attention, with follow-up questions (e.g., How did it make you feel? And what came of that discussion?). We also asked them to provide examples of the best and worst ways someone could bring an animal welfare issue to their attention. We provided scenarios (farmers received a hypothetical report from an animal care assessment that $25 \%$ of their cows were lame or had hock injuries) and follow-up questions and probes (How would that make you feel? and What would you do next?). If the veterinarian was mentioned as someone expected to bring up welfare concerns, we asked follow-up questions (e.g., How might that affect your relationship with your veterinarian?). All participants in all focus groups brought up their veterinarian.

An assistant took notes during the discussion to capture key group elements, such as group dynamics and participant body language (e.g., head nodding, head shaking), to help interpret dialogue using body language (Krueger and Casey, 2015). At the end of each focus group, the facilitator and assistant audiorecorded a debrief and took notes to evaluate group dynamics and achievement of the objectives. Participants did not review the transcripts before analysis by the researcher. To increase rigor, we performed systematic analysis of the transcribed data (Braun and Clarke, 2006). First, we listened to focus group discussions during the live focus groups, and later by listening to the audio-recording multiple times (Braun and Clarke, 2006). After transcription, we read the transcripts of the focus group discussions, and then developed working codes using a qualitative organizational software tool (Quirkos; Quirkos Ltd., Edinburgh, UK), highlighting segments and creating labels in the transcripts. Through careful reading and rereading of the transcripts (Crabtree and Miller, 1999; Creswell, 2007), we created unique codes to label ideas and concepts, and placed them in a preliminary codebook. A second coder used the preliminary codebook to code subsets of the focus groups and identify discrepancies, create new codes, or refine codes until agreement was met, and then codes were placed in a final codebook (Crabtree and Miller, 1999). The transcripts were coded within groups, and we used Quirkos to identify repetition of codes across groups. These codes were connected or separated through an iterative process of developing working themes and subthemes in the data. The themes were aimed at answering the questions of why, how, from whom, and for what reasons farmers would want welfare issues broached and addressed on farm. We used "some farmers" when only 1 or 2 focus groups referenced a subtheme, and "most farmers" when all 5 groups referenced a subtheme. 
We selected the participant quotes in the results section for a variety of purposes (i.e., evidence for theme development, enabling voice of the participants, explanation of themes, and more; Corden and Sainsbury, 2006). Each focus group was assigned a random letter label (e.g., $\mathrm{W}$ or $\mathrm{R}$ ), and then each participant in the group was assigned a number between 1 and 9 , so that quotes could be reported and attributed anonymously to a single participant. For example, farmer 3 in focus group W was assigned the label "Farmer W3" in the results. All quotes have been neutralized for sex, because data were not analyzed or assessed by sex. Quotes have been modified for length and clarity: ellipses indicate where text was omitted to reduce quote length, and brackets indicate the authors' additions to the text.

Ultimately, we synthesized themes to help answer questions about who farmers want welfare advice from, what they expect with the delivery of welfare advice (i.e., expected characteristics and skill sets), how they want welfare topics broached, and what they expect from those providing advice. We also identified potential disconnects between veterinary and producer expectations.

\section{RESULTS}

\section{Demographics}

Five focus groups, consisting of 36 farmers in total, took place in dairy regions in southwestern, central, and eastern Ontario, Canada. Participant ages ranged from 21 to $80 \mathrm{yr}$ (median $=47$ ). Participants' herd size ranged from 25 to 550 (median $=75$ ) lactating cows. Farm type included freestall $(\mathrm{n}=14)$ and tiestall $(\mathrm{n}=$ 22). The sample included 5 female farmers and 31 male farmers. The facilitator and assistant were both female. Farmer-estimated average production ranged from 6,800 to $12,505 \mathrm{~kg} / \mathrm{cow}$ per 305 -d lactation (median $=$ $10,288 \mathrm{~kg}$ ). Each focus group lasted between 108 and $129 \mathrm{~min}$.

\section{Thematic Analysis}

Among all focus groups, farmers were congruent on welfare issues and priorities, and they identified the following as the main welfare issues on dairy farms: lameness, cattle handling, dehorning practices, injuries (i.e., hock injuries), calf care, transition cow disease, cull cow transport, down cow/euthanasia, and the general physical health of the cows. Participants had some discourse on whether or not tail docking was a welfare concern. Farmers thought that consumers might identify pasture access, tie stalls, trainers, cow-calf separation, and group housing as additional welfare issues.
The themes and subthemes we identified through analysis are depicted in a thematic map in Figure 1. For clarity, we organized the themes to help answer the following questions: What is expected with delivery of welfare issues? (themes 1-4); How did they want welfare issues broached? (theme 5); and From whom did they want the topics broached? (theme 6).

\section{Theme 1: An Established Relationship Is Important to Farmers When Broaching the Topic of Animal Care}

Consistently and emphatically, farmers from all focus groups said that they wanted an established relationship with anyone who broached animal welfare topics with them and provided advice on animal care or welfare. Farmer V1 defined this as the "... guys that come in every week or month that we trust-and trust their word and trust their advice." Farmers' most prominent reasons for wanting the established relationship were that they trusted that person; that they would be more accepting of advice; and that they felt the person "... understands the industry ... and knows [their] farm specifically and [their] farm goals" (Farmer R3). This sentiment of established relationships resonated among all focus groups, and farmers would often continue each other's thoughts in agreement. The following dialogue is a representative sample:

Farmer C5: Not the government, not the animal welfare people, it has to be somebody that actually knows our farms ...

Farmer C3: Yeah. The guys that work with us already. The veterinarian ...

Farmer C6: They know us.

Farmer C5: Yeah, that's right. That knows what's going on at the farm. And so if they say something, I'll hear them out ... When someone you work with says you have a problem, well yeah, OK ... But if it's just out of the blue, someone comes in and says you have a problem, I don't think it matters what it is, then you just don't like it ... I probably wouldn't agree with [them] ...

Overall, it was common for farmers to state that they were more accepting of animal care advice - and they found it easier to work with advisors and resolve issues - when the advice came from someone they already worked with and who they trusted. It was also important that the person who gave farmers welfare advice was someone who saw their farm over time and knew their farm problems and whether a particular 
problem was consistent one worth working on. Farmer V3 invoked a collective "we," supported by nodding from other farmers when discussing comfort level with and receptivity to veterinary advice: "We feel comfortable working with the veterinarian, because we work with [them] so much, as opposed to a stranger coming in the barn-right away you put your guard up. Like this guy's going to tell me I'm doing something wrong, whereas the veterinarian is there every day ... [they] can recognize that you have a problem, because [they have] seen it over time and know it's a real problem if they are bringing it up." Farmer V3 then immediately followed up with a quote in a different voice, "Let's work at that," and then in their own voice "Well, OK." When probed about the alternate voice, the farmer said that is what their veterinarian could say to them, and that they would be fine with that because "They trust if their vet is telling them there is a problem that there actually is a problem."

Although advice provided by regular consultants about animal care issues such as lameness was gener- ally well received by farmers because of the trusted relationship, they had reservations if the person was new to the farm. For example, Farmer W1 said, "You have a relationship with the guy, that's fine for [them] to bring it up. Sure. But if [they're] new on your scene and [they] start preaching to you, you're going to look for another vet." However, a new veterinarian broaching an animal care topic did result in receptivity for another farmer, as long as the farmer considered the communication tactful. For example, Farmer W3 said, “... It's a personality thing for sure; we have a new vet in our practice, and I really like [that vet]. You're figuring out if you like [them] at first, though. [They] didn't want to, but [they] brought up things, but in a way that was nice. So it is a new vet thing, but also a personality thing." Overall, the broaching of animal care topics by regular on-farm consultants such as hoof trimmers and veterinarians was generally well received, because farmers had an established relationship with them and trusted them.

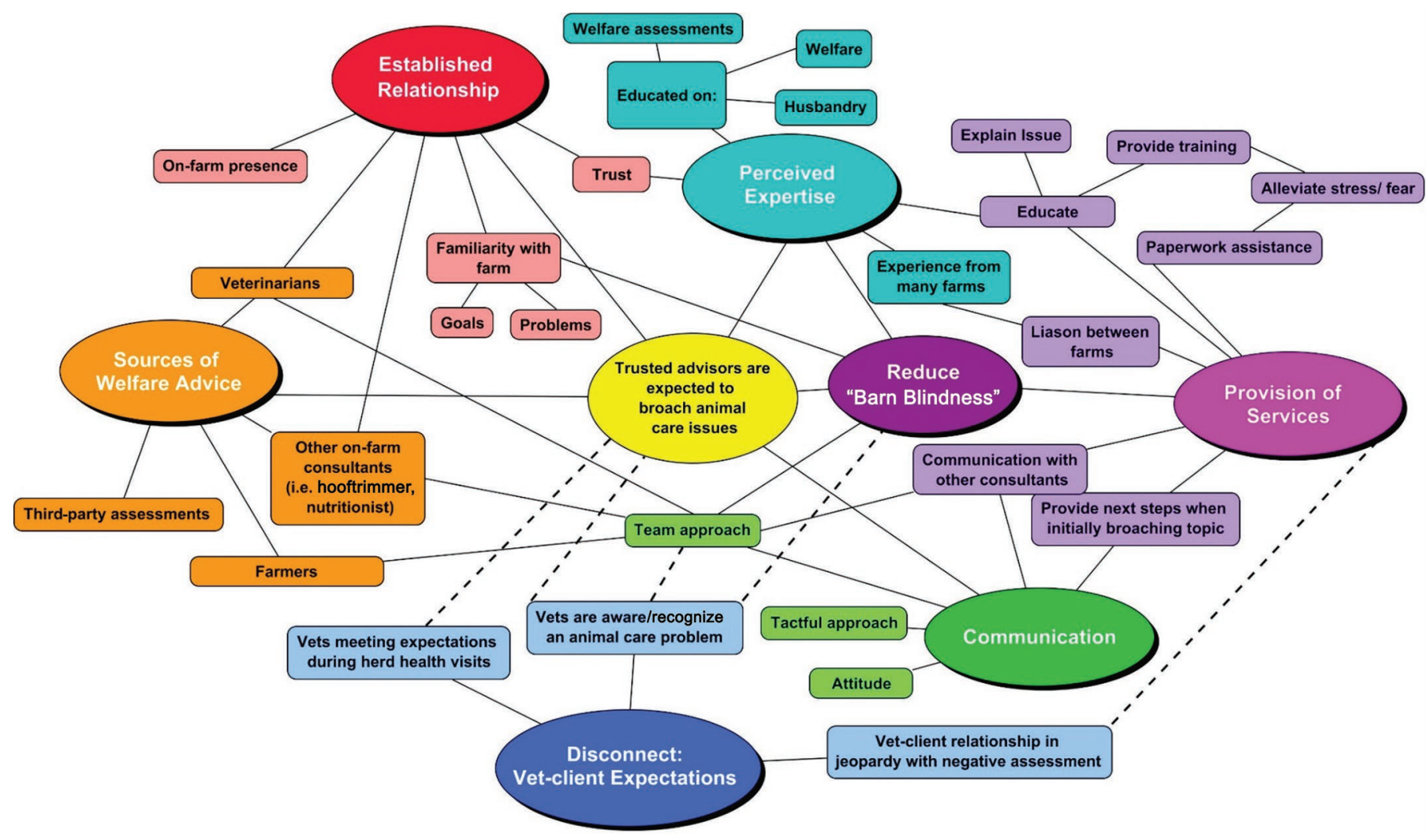

Figure 1. Thematic map of dairy farmers' perceptions representing the major themes (distinct colors) and subthemes for broaching the topic of animal welfare topics on their farm. The dashed lines represent potential disconnects in veterinarian-client expectations. The 6 themes were as follows: (1) an established relationship with the farmer; (2) perception of expertise in dairy care or welfare; (3) reduction of "barn blindness"; (4) provision of practical animal care services or solutions along with identification of problems; (5) communication approach used when broaching animal care issues; and (6) perception of sources of welfare advice. The blue circle and spoked segments with dotted lines represent the authors' viewpoint of potential disconnects between farmer and veterinary expectations for animal welfare issues during herd health visits. Central to the themes were the roles of trusted advisors, including veterinarians. 
Theme 2: Farmers Expect the Person Broaching Animal Welfare Issues on Farm to Be an Expert on Dairy Animal Care

Participants expected welfare advice to be provided by someone who was knowledgeable about animal care and welfare issues, and who had expertise harnessed from many farms. For example, farmer V5 said, "I presume they teach animal care, or proper welfare, to be a veterinarian." Farmer C1 said, "My hoof trimmer knows a lot about hooves, and he has guys come learn from him, and even teaches me some things about caring for hooves, so I know I am getting, you know, good information." Farmers juxtaposed remarks about their "regular guys" with remarks expressing doubt that organizational welfare assessors can really understand animal welfare issues at the farm level. For instance, Farmer R5 said that assessors "... think they can just take a two-week course and know how animals walk, whereas vets are in school for years ... and they see your farm on the good and bad days. They are working with farmers every day." It was important that the person broaching welfare issues had knowledge of animal welfare, but also of solutions. For example, Farmer E2 said, "If I had the veterinarian point [hock injuries] out to me, then I know it's coming from a person that also has the knowledge and experience to tell me how, what I can do to correct the situation. Work with me on it."

Farmers considered advisors to be experts when they had experience from seeing and helping many other farms. For instance, Farmer R6 said, "I guess I always come back to the veterinarian, the veterinarian and the feed rep and even the hoof trimmer. They're actually very good at helping us farmers, telling us what the health of the animal is, because they see hooves every day. They see lots of barns every day." Farmer V5 said, "It gives you direction to go to the veterinarian, or a nutritionist who visits barn after barn after barn in a day. They see everything ... see where you can solve your problem."

\section{Themes 3 and 4: Prevention of "Barn Blindness" Is Important and Animal Care Services Should Be Provided Before and After Welfare Topics Are Broached}

Farmers said that providing animal care services before and after welfare issues are raised is important, and that they expect it from their trusted advisors. Themes 3 and 4 coalesced around this point, and are presented together. To a large extent, participants in all focus groups agreed that they expected trusted consultants to identify animal care issues and inform the farmer about the issues (preventing "barn blindness," a lack of perception of problems in one's own barn); and provide practical next steps for remediation after identifying an issue. To a lesser extent, participants across discussions expected trusted consultants to act as a liaison between farms and other consultants; provide education and training; and provide animal care paperwork support (e.g., standard operating procedures).

Identification of Animal Care Issues and Prevention of "Barn Blindness". Farmers in the focus groups expected advisors to prevent "barn blindness." Although farmers discussed their personal responsibility for animal care, all discussions showed a general consensus that farmers can suffer from "barn blindness," meaning that they do not always see something as abnormal because they become accustomed to seeing it every day. Farmer E5 said, "You go to your farm and you can be blinded to stuff that's happening in your barn. Things start happening that you don't see until somebody else walks in and sees it, because I'll see stuff on other people's farm that I don't necessarily always see on my farm." Farmer R4 specifically referred to the concept as "barn blind," and said, "We can be barn blind, like "oh I didn't realize it was that bad." Participants said that they needed and expected other people (most often they referred to the veterinarian) to help them recognize an animal care problem if they were to address it. This was summarized by Farmer E4, who said, "Sometimes you don't notice things in your barn and having someone you trust come in, tell you need to change something, is good, because if it is a serious problem and you're not seeing it, you're not going to change things."

Farmers consistently and emphatically described the expectation that veterinarians would inform them of welfare issues. In one example, while other farmers nodded their heads in agreement, Farmer R1 said, "I have [veterinarian x] for herd health. If [they're] seeing a problem that I don't see or that I'm not asking [them] about, I'm hoping that [they] have an awareness of it ... I hope that [they're] walking in with open eyes and actually seeing my barn with a fresh eye every time [they] come in." Farmer R6 added that "... we would respect [them] more for telling us."

Farmers expected veterinarians to help them with welfare at the individual cow level, as well as at the group level mentioned above. For instance, 3 participants carried on a dialogue that revealed their expectations and experiences with veterinarians broaching the topic of euthanizing a cow:

Farmer R1: I think veterinarians are pretty good. They are realistic. We [farmers] try our best to know when to cut the cord [euthanize the cow/end the relationship with the cow] too, right.

Farmer R2: And sometimes they need to tell you. 
Farmer R5: It happens.

Farmer R1: Oh, it happens, and ...

Farmer R2: Sometimes the veterinarian tells you, too, before you want to, as well, like geez, one of my best cows, but I'm not ready, I think we can ...

Farmer R3 stops Farmer R2 mid-sentence and role-plays the veterinarian as if a sick cow were in the room:

Farmer R5: No, [R2], it's time to let go.

Farmer R2: Yeah, that's what [they] say. 'You know, she's in pain, it's not going to get good enough, it's time to ...' yeah. There's sometimes those discussions that go on between the farmer and the veterinarian. We need that sometimes.

Discussions such as these made it clear that sometimes veterinarians tell farmers things they do not want to hear, but that the farmers felt they needed and wanted to be told when it pertained to animal care concerns at both the herd and individual levels, because they were not always aware of welfare issues.

Farmers had differing views about what they felt their veterinarian could achieve and would communicate during a herd health visit. Most farmers across focus groups felt that their veterinarian could pick up on herd-level lameness problems during a typical herd health visit, but a few farmers were not so sure. Some farmers were less certain their veterinarian would see herd-level lameness issues. For instance, Farmer R3 said, "I don't think before proAction like any of my vets would ever know there was a lame cow, or really notice hock injuries, or if I had a lame cow on the farm, 'cause they're there for reproduction, they're there for a specific issue."

Some farmers held the view that if their veterinarians did not bring up specific animal care issues such as lameness, they did not have those issues on their farm. Farmer V1 said, "I don't have an issue with lameness. My vet never says anything when [they] come for herd health." In response, other farmers suggested that "Maybe [the veterinarian] just didn't mention it" (Farmer V5). Some farmers said that negative consequences to their veterinarian-client relationship could result if they received negative feedback on an animal care assessment and their veterinarians had not informed them about the animal care issue. Farmer C3 said, "They're supposed to ... they should know what's going on ... they should be able to come in and pick on it. And if they're not doing their job, well, there'll be another one in here next week that'll want my business."
Thus, this farmer suggested that there would be serious consequences, such as changing veterinarians, if their current veterinarian did not meet their expectations for mitigating "barn blindness."

Provision of Practical Next Steps. Participants also discussed the expectation that if someone broached an animal care issue with them, they would want to be given practical next steps to resolve the issue. Farmers acknowledged that it is frustrating to be told you have a problem and not be given solutions. For example, Farmer E2 said that if someone "... pointed out [lameness issues on farm] and, you know, wouldn't give me any answers for what to do. That would bug me to no end." Farmers indicated that they wanted solutions, but they also wanted practical solutions that were consistent with what they felt was achievable on their farm over time. For instance, Farmer W4 stated, "When someone brings up something that's just not logical or practical, that would be a frustrating thing if there's no actual solutions, or you felt there was no solution. My veterinarian, my feed rep, knows my farm and could help me make sense of things." It became apparent that these types of next-step discussions were closely tied to the importance of relationships with farm consultants and their understanding of a farm's current problems.

Provision of Inter-Consultant Collaboration and Farm Liaison Services. Participants said that they would like their trusted consultants to act as a liaison with other farmers who may have had similar problems that had been resolved or improved, to provide them with solutions for their farm's current problems. Farmer W2 said, "Your veterinarian, your feeder, your calf guys, if you can have all those guys on the same page as you, I think you have a lot better idea of how your animals are doing, instead of just trying to do it all yourself." Farmers suggested that working as a team helps to prevent "barn blindness" and resolve animal care issues, but farmers said that this could be done better, and that their consultants often do not work together.

Provision of Welfare Training and Education. Participants identified veterinarians as being able to provide training or information on welfare assessment or welfare-related procedures. Farmers explained that their veterinarians (or in some instances, other veterinarians) provided information sessions about animal care assessments. Farmer V7 said, "the veterinary clinic] has been putting on meetings about this proAction ever since last year ... they're very helpful, too. And even my herd health veterinarian-you ask questions and [they]'ll inform you about it, right. It has made me feel less stressed. I know what I am supposed to be looking for and doing." Some farmers said they did not have 
proactive veterinarians, and they were not receiving guidance for their upcoming animal care assessments. Farmer C3 said, "... going into the proAction thing, we're kind of in the dark of it, you know, we're not really afraid of where our herd's at, but we don't really know where we stand either, right, so. Our veterinarian hasn't been telling us much ... and really, who else should be able to help our farm?" Through recall of past experiences, farmers discussed how important it was for their trusted consultants to educate them on what welfare issues were, show them what a welfare issue (e.g., pain mitigation) looked like, and suggest how to correct it. For instance, Farmer W5 said, "When we were introduced to dehorning calves with pain blockers for the first time, our veterinarian just mentioned it and we told them we didn't know how to do it. They promptly did it, trained us, and within 10 minutes we were doing it. And we've never gone back to that." It was apparent through experiences like these that farmers wanted next steps and training to help solve welfare issues on farm.

Provision of Paperwork Support. Another service participants discussed was help with paperwork. Farmers were very concerned about paperwork (an increase in forms and documentation associated with quality assurance and welfare programs). These are required documents, such as standard operating procedures. Farmers described the additional paperwork as being stressful. For example, during a discussion about the paperwork, Farmer C7 said, "We work 7 days a week already, and then we have to do all that other stuff referring to another participant's comment on paperwork] besides it. That's how I see it. It is a lot." The ability of advisors to synthesize welfare-related protocol data for farmers was seen as valuable and time-saving.

\section{Theme 5: Importance of the Communication Approach when Broaching Animal Care Issues}

Farmers said that they worked diligently to provide the best care for their animals given their current circumstances, and that is was difficult to be told that they had an animal welfare issue, because they took a lot of pride in their animal care. Farmer E7 summarized this concept well: "If you're a good farmer and you like your cows and you love the work you're doing and want to work for them, it's going to hurt you if someone, it doesn't matter what it is, if there's a problem you're not going to like to see it, whatever it is ... lameness ... whatever it is." During the hypothetical scenario, when farmers received reports that a quarter of their cows had lameness or injuries, farmers suggested that their initial response would be to feel "bad" (Farmer C1), "shitty" (Farmer W2), "crappy" (Farmer C3), "defensive" (Farmer R1), "upset" (Farmer V2), or that they may "dwell [on the news]" (Farmer R4). Overall, farmers said that they would have negative emotional responses to hearing that the care of their animals was not meeting expectations.

Farmers connected their negative responses (e.g., feeling bad) to the importance of the communication approach taken when broaching an animal care subject or providing advice on animal care issues. Farmers discussed the importance of consultants having what farmer R2 called a "good attitude" when broaching a subject, and the importance of tact when speaking about specific issues. Farmers said that positive communication helped them be receptive to information, and it mitigated negative emotional responses. Farmer W2 said, "When they deliver the message in an insulting or a demeaning manner, it can really make you feel as though you really don't know what you're doing, or if you're really having a bad week or things aren't going well and then something like that happens, it can just be exacerbated and just seem so much worse, and affect you for days." Farmer R4 said, "I would dwell on it, that's how I would be, I'd be driving tractor or doing the other chores just thinking about it ..." Lack of tact on the part of a consultant may result in negative emotional responses that could adversely affect a farmer.

Farmers suggested examples of tactful approaches. Farmer W1 said, "... not just discussing all the negative things, but also maybe saying what you're doing well" when you broach an animal care issue. Farmer E2 said, "If they just focus on the negative, then that is all you come away with." When probed further, Farmer E2 also said, "It is hard on you to only hear the negative." Participants emphatically suggested that when bringing up an animal care issue, it comes across as less critical if the farmer feels that the advisor wants to work with them to help solve the problem. For instance, Farmer V5 said, "I think the way that they deliver it in terms of there is a problem, they say, 'How can we help?' and that is a far better approach than 'You are doing it wrong' or 'You've got to fix this.'" In another example, farmers had the following dialogue to support this team concept.

Farmer W2: I'd like if they maybe giving ideas on how it could be fixed, how you could address some of the issues together.

Farmer W4: Yeah ... work with you and not be heavy-handed. Goes so much further.

Farmer W3: My veterinarian just went over our procedures. Got a sense of what we were doing, and then offered some help ... I liked that [they] wanted 
to know why we were doing what we were doing, then [they] suggested ideas for us to do together.

Although farmers discussed their desire for consultants to inform them of animal welfare issues with tact, they had different ideas about whether consultants would always inform them. Some farmers said that veterinarians might be worried about farmers' reactions. Farmer R1 said, "Nobody wants to take the risk to be, I don't know how to phrase it, be the bad guy, it's like a passing the buck kind of thing. So the vet could phrase it, 'You know, on your next inspection they're going to flag you.' Do you know what I mean, so [they] don't have to say, 'I see a problem' [they're] going to say, 'They're going to find a problem.'" Thus, for this farmer, the concept of a veterinarian broaching an animal welfare problem was perceived as potentially so difficult that the veterinarian would not want to take responsibility for bringing it up. Farmer E9 summarized the importance of the relationship and the team-centered approach when broaching animal care issues: "Bring coffee. You know? A conversation. Together. Don't just chuck it at me. Makes it easier to swallow ... pun intended [group laughter]... but you know, I mean that."

\section{Theme 6: Who Is Expected to Broach Animal Welfare Topics on Farm}

Drawing from both direct statements and experiences involving veterinarians, farmers, welfare assessors, and other on farm consultants (hoof trimmers, nutritionists, robotic technicians, mattress consultants), veterinarians were referenced emphatically and consistently as having the traits, services, and educational background desired by farmers to broach welfare issues on their farms.

The following dialogue shows nicely how veterinarians meet farmers' expectations for bringing up a welfare issue and providing advice. It incorporates expertise in animal care, alludes to an established relationship history and routine presence on the farm, and it demonstrates an expectation that the veterinarian will help prevent "barn blindness" and resolve an issue:

Farmer V4: I don't think my veterinarian telling me about [hock injuries] would bother me...

Farmer V2: It shouldn't, because the veterinarian is a professional, [they] should...

Farmer V4: Yeah, [they're] prof-

Farmer V1: Well, why would [they] not say something ...

Farmer V6: [They're] an educated professional ...
Farmer V1: [They] tell us other things too that we don't want to hear about ... [all focus group participants began laughing]... that we don't see ... [they] tell you you've got to push the feed, or something like that, you've got to deal with it. It's a part of it all.

Farmer V4: Yeah, yeah, yeah. We respect [them] and [they're] educated professionals, right. [They] should tell us if we have things going on with hocks.

Farmer V2: And they can see you the next week, and the week after to work on it with you.

In addition to veterinarians' skill sets and characteristics, farmers also inherently felt veterinarians had a general responsibility to identify welfare issues. During the discussion, when farmers were asked, "Who do you feel is responsible for overseeing animal care on your farm?" they emphatically stated that they were responsible for the care of their animals. Farmer V1 said, "It's our lifelong mission to be here to look after these animals. It's our job," but every farmer who contributed to these discussions identified the veterinarian as being responsible as well. For example, Farmer W5 said, "The owner has to be responsible for the animals. At the end of the day, it's my responsibility. I'm the farmer and it's up to me. And then there's the veterinarian." Farmers said that veterinarians have a responsibility at the herd level and the individual cow level to identify welfare issues. For example, Farmer R6 said, "I think everybody here has a veterinarian that comes in on a regular basis, and it's their responsibility as a veterinarian, as your veterinarian, looking after your herds, in your best interest for you to do well. If they see a problem ... they're going to, they should tell you. Pretty sure mine will." It was evident that farmers felt strongly that their veterinarian was responsible for informing them of animal welfare issues, but they had some doubt as to whether veterinarians would always broach the subject.

Although hoof trimmers and nutritionists were mentioned in some groups because of established relationships, participants made limited references to the variety of services they could provide, and their lack of expertise in welfare issues. For example, nutritionists and hoof trimmers were mentioned as able to combat lameness through nutrition and hoof care, but they were never mentioned in reference to hock injuries, housing design, or pain control, for example. Third-party assessors were only described as being capable of preventing "barn blindness" by highlighting issues (e.g., hock injuries with a percentage of herd-level prevalence) and providing some general comparisons with other farms. Farmers gave very little trust to third-party groups. Farmer C6 said, "They think they know what they are 
doing with a 6-week course or whatever they get before coming on our farms. They don't even work with farmers. They just give them reports."

Farmers said that they effectively monitored the care of their animals by personally overseeing the cows and by having veterinarians and other consultants come to their farm regularly. For this reason, farmers felt an assessment from an outsider was unnecessary. Farmer R5 said, "I don't see the value. If it wasn't mandated that we have [the proAction Animal Care Assessment], I don't see the value of having another person coming in to assess my cow ... I think I have a good enough assessment of my herd myself with the vet coming in." This farmer expected their current consulting network to be capable of identifying animal welfare issues.

\section{DISCUSSION}

The results of this study show the complexities of broaching animal welfare topics from farmers' point of view, and provide insights for stakeholders who are interested in discussing welfare issues and consulting to work toward solutions. It is important to note that although welfare can be defined as 3 overarching segments - affective state (i.e., how the animal feels), biological functioning (i.e., overall health), and natural living (i.e., the animal's ability to perform behaviors found in nature; Fraser et al., 1997) - the farmers in the focus groups mainly emphasized welfare issues that related to affective state (e.g., general comfort, freedom from pain) and biological functioning (e.g., general health). The results presented here may have been different if farmers were asked to discuss natural behaviors applications of welfare.

This study had some limitations. Because all farmers were Canadian and the context was preparing for the first national animal care assessment, the perspectives described in this study may differ from farmers in other countries, and from farmers who may not be discussing and preparing for a welfare-related assessment program. The qualitative researcher gathering information was a veterinarian who has experience in welfare research, so it is possible that preconceptions may have influenced data collection and analysis. However, we used wellestablished methodological approaches to minimize such bias, including reflexivity, double-coding, and discussion of analytic process with the other investigators.

It was apparent through discussion with farmers that they felt they had an ethical obligation to maintain good welfare through their "pride" and "self-responsibility of care," which was consistent with a previous study in the United Kingdom, in which the most commonly reported motivator for farmers to make lameness improvements was pride in a healthy herd (Leach et al., 2010). Most farmers in the current study felt confident that their trusted consultants, especially their veterinarian, saw so many other farms that they would identify and inform farmers if they saw a welfare issues. Farmers felt that veterinarians were in an ideal position to advise and motivate farmers to improve welfare-related practices, similar to another study that focused on udder health (Lam et al., 2011). Although this was an expectation from the farmers, veterinarians are known to face ethical challenges in food production related to welfare, and have been reported to focus instead on clinical problems or attempt to perform clinical duties while accommodating services to fit with the values of a particular farmer (Meijboom, 2018). The current study helps provide insight that farmers, even those who self-identify as "difficult," value input on welfare issues, especially when the information is given tactfully by trusted consultants. The concept of trusted consultants seeing and unofficially comparing many farms became very important to farmers' receptivity to and trust in welfare advice. The knowledge, experience, and relationship with the farm and the farmer that participants expected of veterinarians appeared to give legitimacy to the veterinarian to broach welfare issues and provide advice. Standardized benchmarking of welfare is an important motivator for calf management (Sumner et al., 2018). When farmers become aware of issues (e.g., "barn blindness"), they can better address self-responsibility and be motivated to change behavior. A possible solution could be to have veterinarians help with the delivery of results from more standardized assessments by third-party groups, because veterinarians are trusted and also seen as motivators for change.

Theoretical models can be applied to this type of research, such as the Health Belief Model (Montanaro and Bryan, 2014) and the Precaution Adoption Process Model (Weinstein et al., 2008), both of which attempt to explain how groups and individuals feel, decide to take action, and translate a decision into action. Farmers in this study moved along stages such as those described in the above models when they made decisions about animal welfare topics. These models look at various factors (e.g., awareness of an issue and perceived susceptibility to issue) that affect decision-making and behaviors. In the Precaution Adoption Process Model, a farmer might fall into the "unaware" or "unengaged" stages on an animal welfare issue. This is best illustrated by the comments suggesting that farmers can be "barn blind." Farmers would first have to perceive that they have an animal care issue before they can become motivated to change. The intertwining of themes in the current study revealed that for farmers to move away 
from "unaware" or "unengaged" and into "perception of a problem," they need to be prompted by communication with trusted consultants. Farmers suggested that they would be less receptive or even unreceptive if they were engaged by people they did not have a trusted relationship with, potentially leaving them in an unaware or unengaged stage.

We observed some very important disconnects through discussion about veterinarian-client expectations. Veterinarians may not realize that some farmers assume that if the veterinarian says nothing, welfare is not an issue on their farm and that their care is in line with industry standards. This may be establishing a false sense of good animal welfare on a farm and contributing to discrepancies in farmers' estimates versus measures of welfare issues on farm. For example, when asked to self-assess lameness on their farm, farmers missed two-thirds of lame cows (Cutler et al., 2017; Croyle et al., 2018).

In another study, farmers identified the prevention of organizational blindness as the second most important reason to participate in a herd health program (Derks et al., 2012), and in the current study farmers identified preventing "barn blindness" as a critical part of improving welfare through herd health programs. This aligned with farmers' expectations that their veterinarian or other trusted consultant would inform them if they had an animal care issue on their farm. Although less likely because they see varying farms from day to day, consultants might also become "barn blind" to farms they see on a regular basis. A future study should investigate the perceptions of veterinarians, and target training to help facilitate the process of broaching welfare concerns.

Because of the potential consequences of failure to tell a farmer about welfare issues - the expectation of animal welfare education (Theme 2) and desire for teamwork and tactful communication (Theme 5) -it is important that veterinarians receive education and training in both areas so that they can be well received by farmers and meet expectations when broaching animal care topics. Veterinarians continue to receive in-depth training on the management of health issues, but only in recent years have they been offered welfare-related electives for dairy cattle (e.g., https://www.uoguelph .ca/ccsaw/dairy-care-program). Although veterinarians are tasked with the prevention of suffering, through their oaths, there are no clearly established guidelines for engaging in communication that informs a farmer about an animal welfare issue on their farm. Based on our results, the teamwork concept was very important when communicating about welfare with the farmer. This type of communication falls under "relationshipcentered care," where there is shared responsibility for decision-making and share accountability for outcomes (Roter, 1997); in this way, clients become equal stakeholders and are more committed to co-developing strategies (Cornell and Kopcha, 2007). Veterinarians may benefit from communication courses that discuss not only professional communication for health care, but also methods for demonstrating respect toward owners, and word choices and tactics that would establish teamwork and relationship-centered communication (Bard et al., 2017), especially when handling sensitive topics such as welfare. Using joint pronouns such as "we" can be used in directive discourse from doctor to patient or veterinarian to client, where the authoritative figure disguises "we" as a way to give directions without including the perspectives of the patient or client (Skelton et al., 2002; Bard et al., 2017). In the current study, farmers appreciated the use of the "we" and "our" when the "we" was inclusive of a mutual understanding, and where both perspectives were taken into account. In human medicine, studies have shown that communication training can help medical professionals deliver bad news more successfully (Back et al., 2007).

In a previous study, animal welfare was highly valued by farmers, but the dominant view of veterinarians was that farmers focused mainly on production and financial performance (Kristensen and Jakobsen, 2011). In the current study, participants had strong expectations that the veterinarian would broach animal welfare topics. In human medicine, primary care clinicians perceived discussions about childhood obesity as adversely affecting the clinician-patient (caregiver) relationship, because it was a difficult and sensitive topic that could make a caregiver feel criticized (Walker et al., 2007). Although this is a very different scenario from the one explored in the current study, in both cases a consultant is identifying a patient care problem to the primary caretaker, who is not the subject of concern but who may be personally affected by the discussion. A future qualitative study should be done to identify veterinary perceptions and see if expectations align, because it has been suggested that the veterinarian's perception of their client's expectations from herd health visits often differ from what their clients expect (Kristensen and Enevoldsen, 2008; Derks et al., 2013).

\section{CONCLUSIONS}

Broaching animal welfare topics can be a sensitive topic, and that advice is best received when it comes from trusted consultants who use a relationshipcentered approach to discuss welfare on farm. This study provides insight into what might affect farmers' receptivity to discussions about welfare. Farmers in 
this study relied on their trusted consultants, especially veterinarians, to inform them about welfare problems on their farms because they were aware that they could be "barn blind."

\section{ACKNOWLEDGMENTS}

Funding for this project was provided through the Dairy Cluster II by Dairy Farmers of Canada, Agriculture and Agri-Food Canada, the Canadian Dairy Network, and the Canadian Dairy Commission. Data analysis and preparation of the manuscript were performed independently of the project funders. The authors declare no conflicts of interest. We thank the dairy farmers who participated in the focus group discussions; their expertise and experience were invaluable.

\section{REFERENCES}

Back, A. L., R. M. Arnold, W. F. Baile, K. A. Fryer-Edwards, S. C. Alexander, G. E. Barley, T. A. Gooley, and J. A. Tulsky. 2007. Efficacy of communication skills training for giving bad news and discussing transitions to palliative care. Arch. Intern. Med. 167:453-460. https://doi.org/10.1001/archinte.167.5.453.

Bard, A. M., D. C. J. Main, A. M. Haase, H. R. Whay, E. J. Roe, and K. K. Reyher. 2017. The future of veterinary communication: Partnership or persuasion? A qualitative investigation of veterinary communication in the pursuit of client behaviour change. PLoS One 12:e0171380. https://doi.org/10.1371/journal.pone.0171380.

Bauman, C. A., H. W. Barkema, J. Dubuc, G. P. Keefe, and D. F. Kelton. 2016. Identifying management and disease priorities of Canadian dairy industry stakeholders. J. Dairy Sci. 99. https://doi .org/10.3168/jds.2016-11057.

Braun, V., and V. Clarke. 2006. Using thematic analysis in psychology. Qual. Res. Psychol. 3:77-101. https://doi.org/10.1191/ 1478088706qp063oa.

Bruijnis, M., H. Hogeveen, C. Garforth, and E. Stassen. 2013. Dairy farmers' attitudes and intentions towards improving dairy cow foot health. Livest. Sci. 155:103-113. https://doi.org/10.1016/j.livsci .2013.04.005.

Cohen, D. J., and B. F. Crabtree. 2008. Evaluative criteria for qualitative research in health care: Controversies and recommendations. Ann. Fam. Med. 6:331-339. https://doi.org/10.1370/afm.818.

Corden, A., and R. Sainsbury. 2006. Using verbatim quotations in reporting qualitative social research: Researchers' views. Social Policy Research Unit, University of York, York, UK.

Cornell, K. K., and M. Kopcha. 2007. Client-veterinarian communication: skills for client centered dialogue and shared decision making. Vet. Clin. North Am. Small Anim. Pract. 37:37-47. https://doi .org/10.1016/j.cvsm.2006.10.005.

Crabtree, B. F., and W. L. Miller. 1999. Doing Qualitative Research. Sage Publications, Thousand Oaks, CA.

Croyle, S. L., C. G. R. Nash, C. Bauman, S. J. LeBlanc, D. B. Haley, D. K. Khosa, and D. F. Kelton. 2018. Training method for animalbased measures in dairy cattle welfare assessments. J. Dairy Sci. 101:9463-9471. https://doi.org/10.3168/jds.2018-14469.

Creswell, J. W. 2007. Qualitative Inquiry and Research Design, Choosing Among Five Approaches. 2nd ed. Sage, Thousand Oaks, CA.

Cutler, J. H. H., J. Rushen, A. M. de Passillé, J. Gibbons, K. Orsel, E. Pajor, H. W. Barkema, L. Solano, D. Pellerin, D. Haley, and E. Vasseur. 2017. Producer estimates of prevalence and perceived importance of lameness in dairy herds with tiestalls, freestalls, and automated milking systems. J. Dairy Sci. 100. https://doi.org/10 $.3168 /$ jds.2017-13008.
Derks, M., L. M. A. van de Ven, T. van Werven, W. D. J. Kremer, and H. Hogeveen. 2012. The perception of veterinary herd health management by Dutch dairy farmers and its current status in the Netherlands: A survey. Prev. Vet. Med. 104:207-215. https://doi .org/10.1016/j.prevetmed.2011.12.019.

Derks, M., B. van Woudenbergh, M. Boender, W. Kremer, T. van Werven, and H. Hogeveen. 2013. Veterinarian awareness of farmer goals and attitudes to herd health management in the Netherlands. Vet. J. 198:224-228. https://doi.org/10.1016/j.tvjl.2013.07 .018 .

Easton, G. 2002. Marketing: A critical realist approach. J. Bus. Res. 55:103-109. https://doi.org/10.1016/S0148-2963(00)00145-4.

Fraser, D., D. Weary, E. Pajor, and B. Milligan. 1997. A scientific conception of animal welfare that reflects ethical concerns. Anim. Welf. 6:187-205.

Kaler, J., and L. E. Green. 2013. Sheep farmer opinions on the current and future role of veterinarians in flock health management on sheep farms: A qualitative study. Prev. Vet. Med. 112:370-377. https://doi.org/10.1016/j.prevetmed.2013.09.009.

Kristensen, E., and C. Enevoldsen. 2008. A mixed methods inquiry: How dairy farmers perceive the value(s) of their involvement in an intensive dairy herd health management program. Acta Vet. Scand. 50:50. https://doi.org/10.1186/1751-0147-50-50.

Kristensen, E., and E. B. Jakobsen. 2011. Challenging the myth of the irrational dairy farmer: Understanding decision-making related to herd health. N. Z. Vet. J. 59:1-7. https://doi.org/10.1080/ 00480169.2011.547162.

Krueger, R. A., and M. A. Casey. 2015. Focus Groups: A Practical Guide for Applied Research. Sage, Thousand Oaks, CA.

Lam, T. J., J. Jansen, B. H. van den Borne, R. J. Renes, and H. Hogeveen. 2011. What veterinarians need to know about communication to optimise their role as advisors on udder health in dairy herds. N. Z. Vet. J. 59:8-15. https://doi.org/10.1080/00480169 .2011 .547163 .

Leach, K. A., H. R. Whay, C. M. Maggs, Z. E. Barker, E. S. Paul, A. K. Bell, and D. C. J. Main. 2010. Working towards a reduction in cattle lameness: 1. Understanding barriers to lameness control on dairy farms. Res. Vet. Sci. 89:311-317. https://doi.org/10.1016/j .rvsc.2010.02.014.

LeBlanc, S. J., K. D. Lissemore, D. F. Kelton, T. F. Duffield, and K. E. Leslie. 2006. Major advances in disease prevention in dairy cattle. J. Dairy Sci. 89:1267-1279. https://doi.org/10.3168/jds.S0022 $-0302(06) 72195-6$.

MacDougall, C., and F. Baum. 1997. The devil's advocate: A strategy to avoid groupthink and stimulate discussion in focus groups. Qual. Health Res. 7:532-541. https://doi.org/10.1177/ 104973239700700407.

Malterud, K. 2001. Qualitative research: Standards, challenges, and guidelines. Lancet 358:483-488. https://doi.org/10.1016/S0140 $-6736(01) 05627-6$.

Meijboom, F. L. B. 2018. More than just a vet? Professional integrity as an answer to the ethical challenges facing veterinarians in animal food production. Food Ethics 1:209-220. https://doi.org/10 $.1007 / \mathrm{s} 41055-017-0019-\mathrm{z}$.

Mench, J. A. 2003. Assessing animal welfare at the farm and group level: A United States perspective. Anim. Welf. 12:493-503.

Montanaro, E. A., and A. D. Bryan. 2014. Comparing theory-based condom interventions: Health belief model versus theory of planned behavior. Health Psychol. 33:1251-1260. https://doi.org/10.1037/ a0033969.

Morgan, C. A. 2009. Stepping up to the plate: Animal welfare, veterinarians and ethical conflicts. PhD Thesis. University of British Columbia, Vancouver, Canada.

Roter, D. L. 1997. Communication patterns of primary care physicians. JAMA 277:350-356. https://doi.org/10.1001/jama.277.4 .350 .

Skelton, J. R., A. M. Wearn, and F. R. Hobbs. 2002. "I" and "we": A concordancing analysis of how doctors and patients use first person pronouns in primary care consultations. Fam. Pract. 19:484488. https://doi.org/10.1093/fampra/19.5.484. 
Storbacka, K., and S. Nenonen. 2009. Customer relationships and the heterogeneity of firm performance. J. Bus. Ind. Mark. 24:360-372. https://doi.org/10.1108/08858620910966246.

Sumner, C. L., M. A. G. von Keyserlingk, and D. M. Weary. 2018. How benchmarking motivates farmers to improve dairy calf management. J. Dairy Sci. 101. https://doi.org/10.3168/jds.2017-13596.

Tong, A., P. Sainsbury, and J. Craig. 2007. Consolidated criteria for reporting qualitative research (COREQ): A 32-item checklist for interviews and focus groups. Int. J. Qual. Health Care 19:349-357. https://doi.org/10.1093/intqhe/mzm042.

von Keyserlingk, M. A., A. Barrientos, K. Ito, E. Galo, and D. M. Weary. 2012. Benchmarking cow comfort on North American freestall dairies: Lameness, leg injuries, lying time, facility design, and management for high-producing Holstein dairy cows. J. Dairy Sci. 95:7399-7408. https://doi.org/10.3168/jds.2012-5807.

Walker, O., M. Strong, R. Atchinson, J. Saunders, and J. Abbott. 2007. A qualitative study of primary care clinicians' views of treating childhood obesity. BMC Fam. Pract. 8:50. https://doi.org/10 $.1186 / 1471-2296-8-50$.

Weinstein, N. D., P. M. Sandman, S. J. Blalock, K. Glanz, B. K. Rimer, and K. Viswanath. 2008. The precaution adoption process model. Pages 123-147 in Health Behaviour and Health Education: Theory, Research and Practice. K. Glanz, B. K. Rimer, and K. Viswanath, ed. Jossey-Bass, San Francisco, CA. 